\title{
Chigger mites (Acari: Trombiculidae) new to the fauna of Cuba, with the description of two new species
}

\author{
Milan Daniel $^{1}$ and Alexandr A. Stekol'nikov ${ }^{2}$ \\ ${ }^{1}$ School of Public Health, Institute for Postgraduate Medical Education, Ruská 85, 10005 Prague 10, Czech Republic; \\ ${ }^{2}$ Zoological Institute, Russian Academy of Sciences, Universitetskaya Embankment 1, Saint-Petersburg 199034, Russia
}

Key words: Acari, chiggers, Hyponeocula monocoxalae, Perates nudosetosus, taxonomy, parasites, Cuba

\begin{abstract}
Two new species of chigger mites, Hyponeocula monocoxalae sp. $\mathrm{n}$. from bats and reptiles, and Perates nudosetosus sp. n. from bats, are described. The first finding of larvae of Tectumpilosum negreai Feider, 1983 in nature is reported from a bat collected at the type locality, and the description of this species is emended. Four species, Perates monops (Brennan et Jones, 1960), Parasecia manueli (Brennan et Jones, 1960), Beamerella acutascuta Brennan, 1958, and Blankaartia sinnamaryi (Floch et Fauran, 1956), are recorded for the first time in Cuba and on new host species.
\end{abstract}

Intensive faunistic study of Cuban chiggers was begun just recently (de la Cruz and Socarrás 1993, de la Cruz and Daniel 1994). It was based on collections made in 1965-1985 by Czechoslovak-Cuban joint expeditions. The present paper continues this work. It includes descriptions of two species new to science, a redescription of one species and data on four species new to the Cuban fauna.

\section{MATERIALS AND METHODS}

The chiggers were collected in 1965-1966 by Drs. V. Černý, F. Dusbábek, M. Daniel, J. de la Cruz and other Czech and Cuban zoologists (de la Cruz and Daniel 1994). The individual collectors are not noted in particular collections in the field collector's protocols and therefore, their names are not mentioned below. Hosts were determined by Drs. G. Silva-Taboada (bats) and O.H. Garrido (birds and reptiles). Mites were mounted in Hoyer's medium or in de FaureBerlese's medium. All measurements are in micrometres $(\mu \mathrm{m})$. In the tables, " $n$ " indicates sample size for those structures measured. If a structure is unpaired, $\mathrm{n}$ coincides with the number of specimens measured (excluding those in which the structure was damaged or distorted and could not be measured). For paired structures $n$ is about twice the number of specimens measured. Terminology follows that of Goff et al. (1982), with some adaptation: "ventral setae" (V) - setae on the ventral surface of idiosoma excluding coxal and sternal setae; VS - number of ventral setae; D - dorsal idiosomal setae; DS - number of dorsal idiosomal and humeral setae; TaIII - length of leg III tarsus; TaW - width of leg III tarsus. The specimens examined are deposited in the Zoological Institute of the Russian Academy of Sciences, SaintPetersburg (ZIN), the acarological collection of the Institute of Parasitology, Academy of Sciences of the Czech Republic, České Budějovice (PaÚ), and in the collection of the senior author.

\section{RESULTS}

Genus HYPONEOCULA Vercammen-Grandjean, 1960

\section{Hyponeocula monocoxalae $\mathrm{sp}$. n. Figs. 1-10}

Diagnosis: $\mathrm{SIF}=6 \mathrm{BS}-\mathrm{N}-2-3111.1000 ; \mathrm{fPp}=\mathrm{B} / \mathrm{B} /$ $\mathrm{NNN} ; \mathrm{fCx}=1.1 .1 ; \mathrm{fSt}=2.2$; $\mathrm{fSc}: \mathrm{PL}>\mathrm{AM}>\mathrm{AL} ; \mathrm{Ip}=$ $616 ; \mathrm{fD}=2 \mathrm{H}-6-6-2-2 ; \mathrm{fV}=6-2-2-4 ; \mathrm{DS}=18 ; \mathrm{VS}=14$; $\mathrm{NDV}=32$.

Description: LARVA. Idiosoma. Eyes 2+2. One pair of humeral setae; 16 dorsal idiosomal setae, weakly barbed, arranged 6-6-2-2; 2 pairs of sternal setae and 14 ventral setae, arranged 6-2-2-4; total idiosomal setae 32 . Gnathosoma. Cheliceral blade with tricuspid cap; cheliceral base moderately punctate; gnathobase with few large punctae, bearing a pair of branched setae; galeala nude; palpal claw 2-pronged; setae on palpal femur and genu with 1-2 branches or nude; palpal tibial setae nude; palpal tarsus with 6 branched setae, nude subterminala and tarsala. Scutum. Sparsely punctate with moderate punctae, near trapezoidal, with rounded posterior margin; posterior scutal margin covered with striations, which outlines central angle; AM base at level of AL bases; SB anteriad to level of PL bases; $\mathrm{PL}>\mathrm{AM}>\mathrm{AL}$; flagelliform sensilla with $6-9$ branches in distal half. Legs. All 7-segmented, terminating in a pair of claws and a claw-like empodium. Leg I: coxa with 1 non-specialised branched seta (1B); trochanter 1B; basifemur $1 \mathrm{~B}$; telofemur $5 \mathrm{~B}$; genu $4 \mathrm{~B}, 3$ genualae, microgenuala; tibia $8 \mathrm{~B}, 2$ tibialae, microtibiala; tarsus 22B, tarsala, microtarsala, subterminala, parasubterminala, pretarsala. Leg II: coxa $1 \mathrm{~B}$; trochanter $1 \mathrm{~B}$; basifemur $2 \mathrm{~B}$; telofemur $4 \mathrm{~B}$; genu $3 \mathrm{~B}$, genuala; tibia 6B, 2 tibialae; tarsus 16B, tarsala with somewhat inflated apex, microtarsala, pretarsala. Leg III: coxa 1B; trochanter 1B; basifemur $2 \mathrm{~B}$; telofemur $3 \mathrm{~B}$; genu $3 \mathrm{~B}$, 


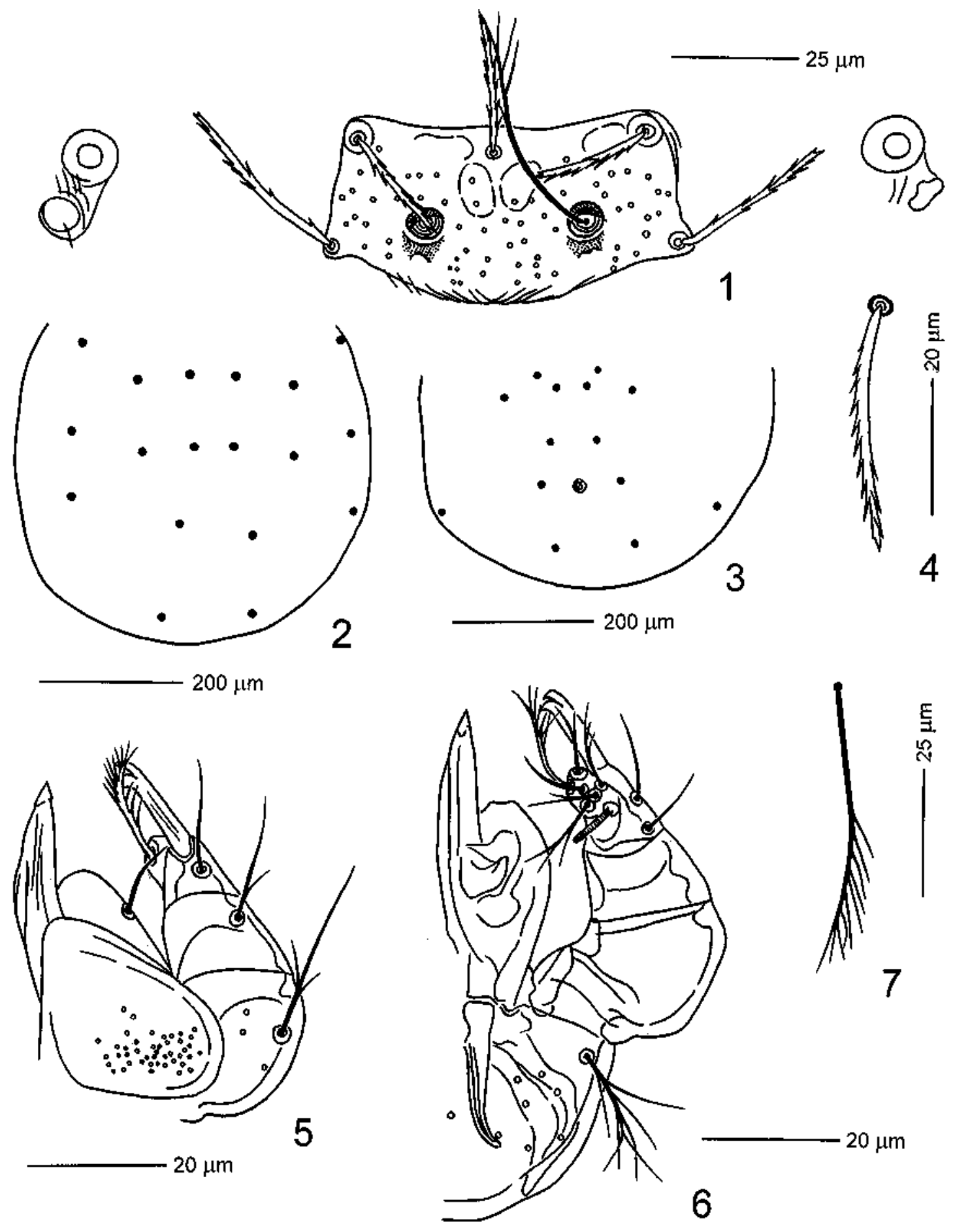

Figs. 1-7. Hyponeocula monocoxalae sp. n., larva. Fig. 1. Scutum and eyes. Fig. 2. Arrangement of dorsal idiosomal setae. Fig. 3. Arrangement of ventral idiosomal setae. Fig. 4. Dorsal idiosomal seta. Fig. 5. Dorsal aspect of gnathosoma. Fig. 6. Ventral aspect of gnathosoma. Fig. 7. Sensillum.

genuala; tibia 6B, tibiala; tarsus 14B, mastitarsala.

$=12, \mathrm{AP}=22, \mathrm{AM}=25, \mathrm{AL}=22, \mathrm{PL}=34, \mathrm{~S}=48, \mathrm{H}=$

Standard measurements of holotype: $\mathrm{AW}=54, \quad 36, \mathrm{D}=27-35, \mathrm{~V}=23-32$, pa $=211, \mathrm{pm}=176, \mathrm{pp}=$ $\mathrm{PW}=65, \mathrm{SB}=31, \mathrm{ASB}=21, \mathrm{PSB}=15, \mathrm{SD}=36, \mathrm{P}-\mathrm{PL} \quad 205, \mathrm{Ip}=592, \mathrm{TaIII}=49, \mathrm{TaW}=12$. 


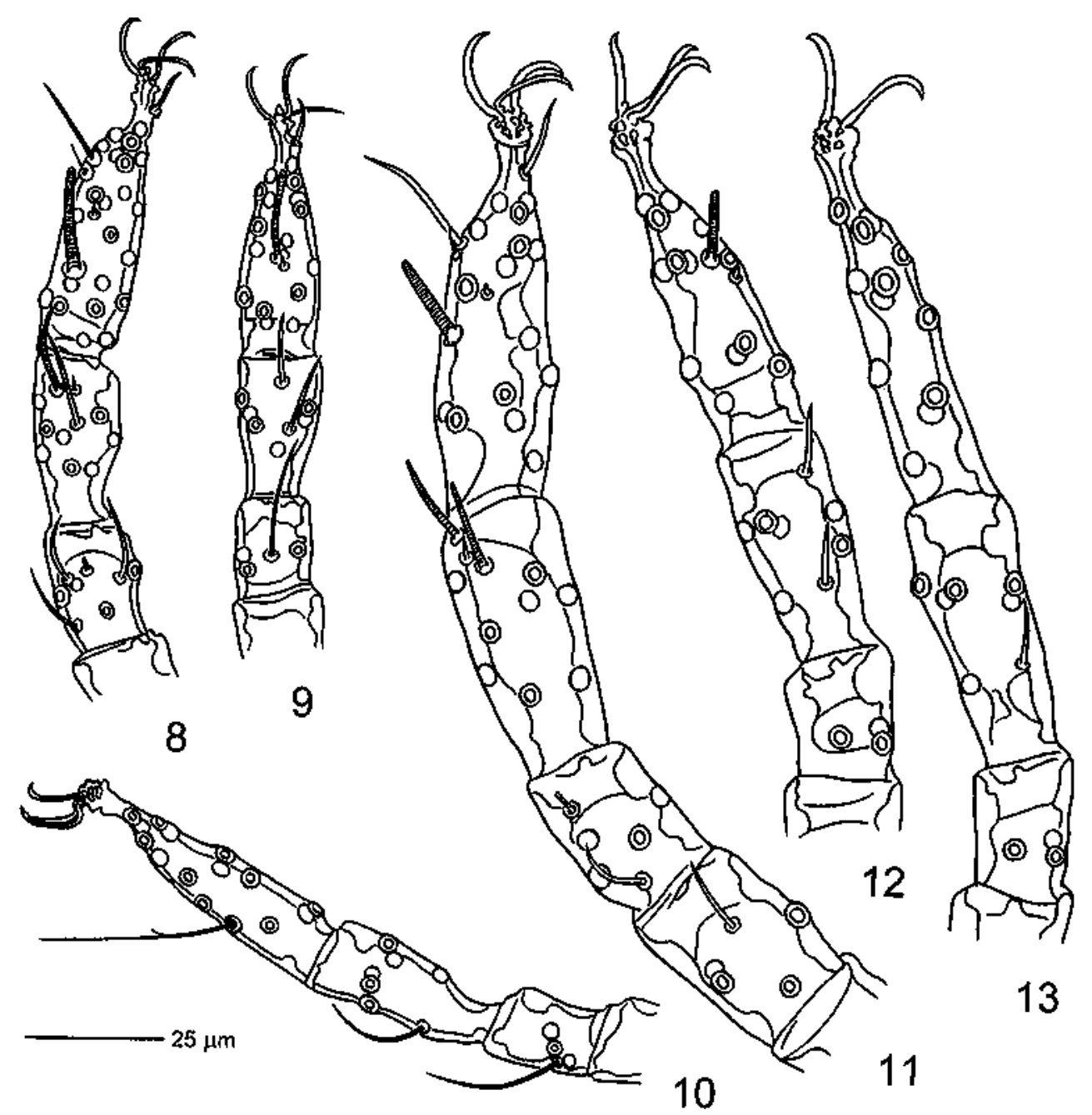

Figs. 8-10. Hyponeocula monocoxalae sp. n., larva. Fig. 8. Leg I. Fig. 9. Leg II. Fig. 10. Leg III. Figs. 11-13. Perates nudosetosus sp. n., larva. Fig. 11. Leg I. Fig. 12. Leg II. Fig. 13. Leg III.

\section{Standard measurements of the type series:}

\begin{tabular}{lccccccc}
\hline & AW & PW & SB & ASB & PSB & SD & P-PL \\
\hline Min & 54 & 64 & 29 & 20 & 15 & 36 & 12 \\
Max & 58 & 69 & 31 & 22 & 17 & 38 & 14 \\
$\mathrm{~m}$ & 56 & 66 & 30 & 20 & 16 & 36 & 13 \\
$\mathrm{n}$ & 7 & 7 & 7 & 7 & 7 & 7 & 7 \\
\hline & & & & & & & \\
\hline AP & AM & AL & PL & S & H & D & V \\
\hline 18 & 25 & 22 & 32 & 45 & 36 & $27-35$ & $23-32$ \\
23 & 33 & 26 & 39 & 50 & 40 & $29-38$ & $26-32$ \\
20 & 30 & 24 & 37 & 48 & 38 & $28-36$ & $25-32$ \\
14 & 6 & 12 & 13 & 8 & 10 & 7 & 3 \\
\hline
\end{tabular}

\begin{tabular}{cccccc}
\hline pa & pm & pp & Ip & TaIII & TaW \\
\hline 211 & 176 & 205 & 592 & 49 & 11 \\
225 & 191 & 223 & 639 & 54 & 12 \\
218 & 185 & 213 & 616 & 51 & 12 \\
3 & 3 & 3 & 3 & 6 & 6 \\
\hline
\end{tabular}

H o s $\mathrm{t}$ s : Natalus lepidus (Gervais, 1837) (Mammalia, Chiroptera, Natalidae), Pteronotus quadridens (Gundlach, 1840) (Mammalia, Chiroptera, Mormoopidae), Anolis bartschi (Cochran, 1928) (Reptilia, Squamata, Iguanidae).
T y p e d a t a : Holotype larva (C-332, T-Tr.-19), Habana Province, Guanajay, Cueva de William Palmer, 12 Aug. 1965, from N. lepidus. 10 paratypes: 5 larvae, same data; 1 larva, Pinar del Rio Province, Vinales, Cueva del Indio, 20 Aug. 1965, from P. quadridens; 4 larvae, Pinar del Rio Province, Vinales, Valle de San Vincente, 20 Aug. 1965, from A. bartschi. The holotype and six paratypes (C-326, C-333, C-337, C-339, C-340, C-352) are deposited in ZIN; two paratypes (C-324, C-327) are deposited in the Institute of Parasitology, Academy of Sciences of the Czech Republic (coll. No. PaÚ 1988, PaÚ 1989); two paratypes (C-330, $\mathrm{C}-335)$ are deposited in the collection of the senior author.

E t y m o log y: The species name "monocoxalae" refers to the presence of only one seta on each coxa.

Differential diagnosis: Hyponeocula monocoxalae differs from all other Hyponeocula species in having 1 seta on coxa III ( $\mathrm{fCx}=1.1 .1)$ against $2-4$ and 2-pronged palpal claw (against 3-pronged). It is most similar to $H$. spathi (Loomis et Tanigoshi, 1968) and differs from this 
species, in addition to above features, in having nude ventral tibial seta $(\mathrm{fPp}=\mathrm{B} / \mathrm{B} / \mathrm{NNN}$ against $\mathrm{B} / \mathrm{B} / \mathrm{NNB})$, number of idiosomal setae more than two times fewer $(\mathrm{NDV}=32$ against 82$)$ and in some measured characters $(\mathrm{PW}=64-69$ against $73-78, \mathrm{SB}=29-31$ against 21-24, AP $=18-23$ against 26-29).

\section{Genus PERATES Brennan et Dalmat, 1960}

Perates nudosetosus sp. $\mathrm{n}$.

Figs. 11-22

Diagnosis: $\mathrm{SIF}=5 \mathrm{~B} ?-\mathrm{N}-2-1001.0000 ; \mathrm{fPp}=\mathrm{N} / \mathrm{N} /$ $\mathrm{NNN}$; fCx $=1.1 .1 ; \mathrm{fSt}=2.2$; fSc: $\mathrm{PL}>\mathrm{AL}>\mathrm{AM} ; \mathrm{Ip}=$ 872; fD = 2H-6-6-2-4-2; fV = 4-4-4-2; DS = 22; VS = $14 ; \mathrm{NDV}=36$.

Description: LARVA. Idiosoma. Eyes absent. One pair of humeral setae; 20 dorsal idiosomal setae, thick and supplied with thick short barbs, arranged 6-6-2-4-2; 2 pairs of sternal setae, anterior nude, posterior with few small barbs in distal part; 13-15 ventral setae with few small barbs, arranged 4-4-4-2; total idiosomal setae 3537. Gnathosoma. Cheliceral blade with tricuspid cap; cheliceral base moderately punctate, with lateral angle; gnathobase sparsely punctate, significantly wider than long, bearing a pair of nude setae; galeala thick and nude; palpal claw 2-pronged; setae on palpal femur, genu and tibia nude; palpal tarsus with tarsala and about 5 nude setae (palpal tarsus not clearly visible in all specimens examined). Scutum. Moderately punctate, trapezoidal, with biconcave anterior and concave posterior margins; $\mathrm{AM}$ base at level of $\mathrm{AL}$ bases; $\mathrm{AM}$ and AL situated on anterior projections of scutum; SB slightly anteriad to level of PL bases; PL $>$ AL $>$ AM, AM very short and nude, AL similar to ventral setae, PL similar to dorsal setae; sensilla flagelliform and nude. Legs. All 7-segmented, terminating in a pair of claws and a claw-like empodium. Leg I: coxa $1 \mathrm{~B}$; trochanter 1B; basifemur 1B; telofemur 4B, short femorala; genu $4 \mathrm{~B}$, genuala, microgenuala long and rod-like; tibia $8 \mathrm{~B}, 2$ tibialae, microtibiala; tarsus $15 \mathrm{~B}$, tarsala, microtarsala, subterminala, parasubterminala, pretarsala. Leg II: coxa $1 \mathrm{~B}$; trochanter 1B; basifemur $2 \mathrm{~B}$; telofemur $4 \mathrm{~B}$; genu $3 \mathrm{~B}$, genuala absent; tibia 6B, 2 tibialae; tarsus 13B, distal tarsala, microtarsala; pretarsala absent. Leg III: coxa 1B; trochanter $1 \mathrm{~B}$; basifemur $2 \mathrm{~B}$; telofemur $3 \mathrm{~B}$; genu $3 \mathrm{~B}$, genuala absent; tibia $6 \mathrm{~B}$, tibiala; tarsus $12 \mathrm{~B}$.

Standard measurements of holotype: $\mathrm{AW}=68$, $\mathrm{PW}=85, \mathrm{SB}=29, \mathrm{ASB}=21, \mathrm{PSB}=10, \mathrm{SD}=31, \mathrm{P}-\mathrm{PL}$ $=8, \mathrm{AP}=21, \mathrm{AM}=17, \mathrm{AL}=23, \mathrm{PL}=52, \mathrm{H}=45, \mathrm{D}=$ $41-49, \mathrm{~V}=27-43, \mathrm{pa}=297, \mathrm{pm}=268, \mathrm{pp}=283, \mathrm{Ip}=$ $848, \mathrm{DS}=22, \mathrm{VS}=14, \mathrm{NDV}=36, \mathrm{TaIII}=70, \mathrm{TaW}=$ 14.

\section{Standard measurements of the type series:}

\begin{tabular}{lcccccccc}
\hline & AW & PW & SB & ASB & PSB & SD & P-PL & AP \\
\hline Min & 68 & 85 & 29 & 21 & 10 & 31 & 7 & 20 \\
Max & 73 & 86 & 30 & 22 & 12 & 33 & 8 & 23 \\
m & 71 & 85 & 29 & 21 & 11 & 32 & 8 & 21 \\
n & 4 & 4 & 4 & 4 & 4 & 4 & 4 & 8
\end{tabular}

\begin{tabular}{cccccccc}
\hline AM & AL & PL & H & D & V & pa & pm \\
\hline 11 & 18 & 52 & 45 & $38-47$ & $25-42$ & 297 & 268 \\
17 & 23 & 59 & 48 & $44-51$ & $27-43$ & 306 & 281 \\
14 & 21 & 55 & 47 & $41-49$ & $26-43$ & 302 & 276 \\
4 & 7 & 5 & 6 & 4 & 2 & 4 & 4 \\
\hline & & & & & & & \\
\cline { 1 - 6 } pp & Ip & DS & VS & NDV & TaIII & TaW & \\
\cline { 1 - 6 } 283 & 848 & 22 & 13 & 35 & 70 & 13 & \\
304 & 886 & 22 & 15 & 37 & 74 & 14 & \\
294 & 872 & 22 & 14 & 36 & 72 & 14 & \\
4 & 4 & 4 & 4 & 4 & 4 & 4 &
\end{tabular}

H o s t: Pteronotus quadridens (Gundlach, 1840) (Mammalia, Chiroptera, Mormoopidae).

T y p e d a t a : Holotype (C-383, T-Tr.-20) and 5 paratype larvae, Pinar del Rio Province, Vinales, Cueva del Indio, 20 Aug. 1965, from P. quadridens. The holotype and three paratypes (C-381, C-382, C-487) are deposited in ZIN; one paratype (C-380) is deposited in the Institute of Parasitology, Academy of Sciences of the Czech Republic (coll. No. PaÚ 1990); one paratype (C-478) is deposited in the collection of the senior author.

E t y m o 1 o g y: The species name "nudosetosus" refers to the fact that many setae in this species are nude (palpal and anterior sternal setae, galeala, AM, setae on gnathocoxa).

Differential diagnosis: Perates nudosetosus is similar to $P$. anophthalma (Hoffmann, 1960) in the shape of scutum, PL much thicker and longer than AL and AM, shape of gnathobase (which is significantly wider than long), thick galeal seta and arrangement of dorsal idiosomal setae (in $P$. anophthalma $\mathrm{fD}=2 \mathrm{H}-6-6-$ 4-2), but differs in leg chaetotaxy (presence of femorala I, 1 genualae I against 2, absence of pretarsala II, absence of genualae II and III, absence of mastitarsala III), many setae nude (anterior sternal setae, setae of palpi and gnathobase, AM and sensilla), palpal femur and genu without lateral angles, more numerous idiosomal setae $(\mathrm{NDV}=35-37$ against 32$)$, smaller scutum $(\mathrm{AW}=$ 68-73 against 82-91, PW $=85-86$ against $100-108$, SB $=29-30$ against $40-46, \mathrm{SD}=31-33$ against $37-42)$ and AM much shorter (11-17 against 40-43).

Remarks: The placing of this species into the genus Perates is provisional, as was stated for P. anophthalma by Loomis (1969). The pattern of leg chaetotaxy in the new species (presence of femorala I, 1 genualae I, absence of pretarsala II, absence of genualae II and III, decreased numbers of non-specialised tarsal setae) appears to be unique in the subfamily Trombiculinae. But obvious similarities between the both species suggest that the specific features of leg chaetotaxy do not constitute a difference of the generic rank.

\section{Perates monops (Brennan et Jones, 1960)}

Brennan and Jones 1960: 524, fig. 17 (Trombicula); Vercammen-Grandjean 1968: 71 [Myotrombicula (Perates)].

Diagnosis: $\mathrm{SIF}=7 \mathrm{~B}-\mathrm{N}-3-3111.0000 ; \mathrm{fPp}=\mathrm{B} / \mathrm{N} /$ $\mathrm{NNN} ; \mathrm{fCx}=1.1 .1 ; \mathrm{fSt}=2.2 ; \mathrm{fSc}: \mathrm{AM}>\mathrm{PL}>\mathrm{AL} ; \mathrm{Ip}=$ $730 ; \mathrm{fD}=2 \mathrm{H}-[6-6]-[8-8]-8-6-\ldots ; \mathrm{DS}=56 ; \mathrm{VS}=62$; $\mathrm{NDV}=118$. 


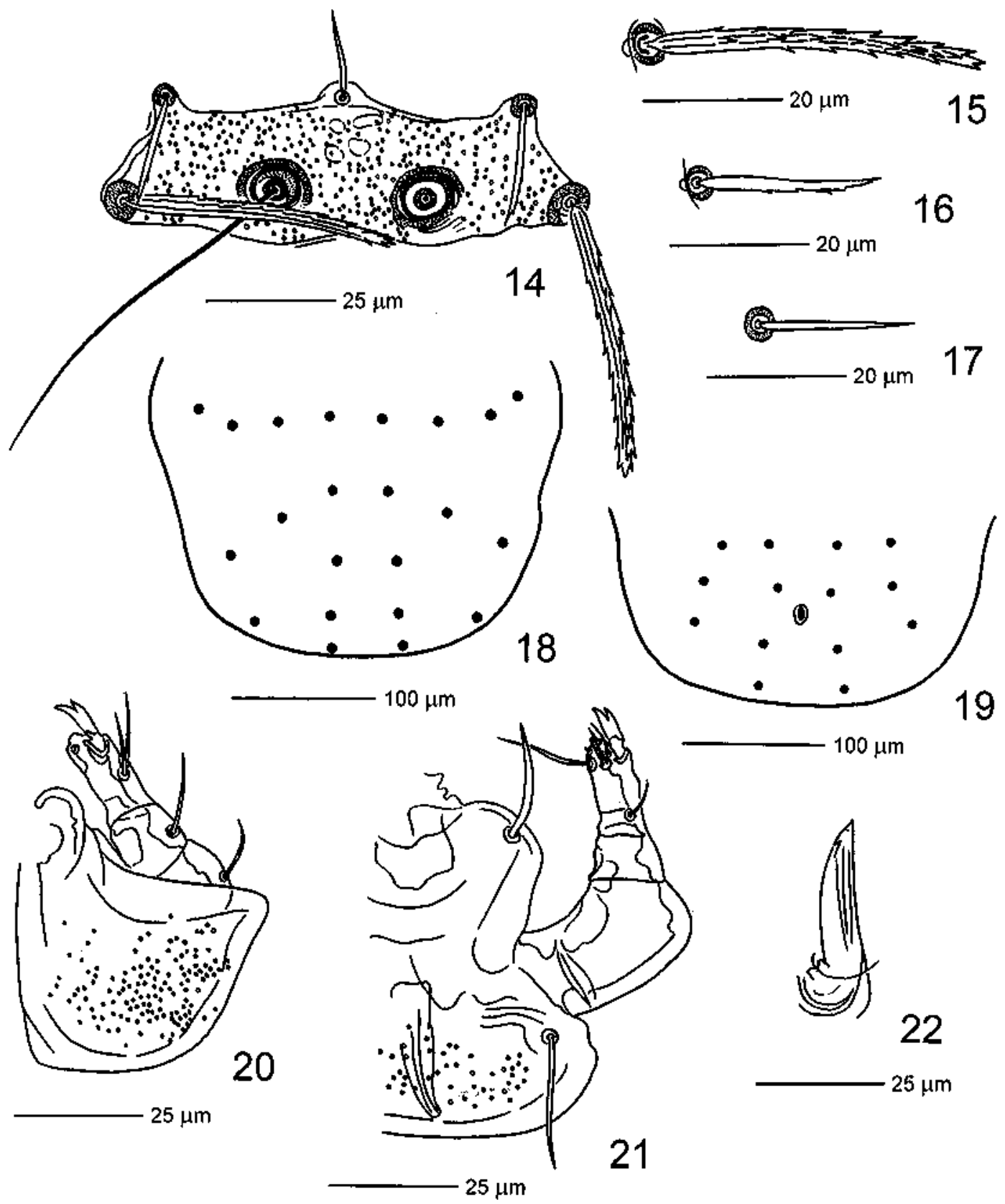

Figs. 14-22. Perates nudosetosus sp. n., larva. Fig. 14. Scutum. Fig. 15. Dorsal idiosomal seta. Fig. 16. Ventral idiosomal seta. Fig. 17. Anterior sternal seta. Fig. 18. Arrangement of dorsal idiosomal setae. Fig. 19. Arrangement of ventral idiosomal setae. Fig. 20. Dorsal aspect of gnathosoma. Fig. 21. Ventral aspect of gnathosoma. Fig. 22. Cheliceral blade.

Standard measurements:

\begin{tabular}{lcccccc}
\hline & AW & PW & SB & ASB & PSB & SD \\
\hline Min & 39 & 59 & 23 & 22 & 11 & 34 \\
Max & 57 & 68 & 28 & 30 & 16 & 44 \\
$\mathrm{~m}$ & 52 & 62 & 25 & 25 & 13 & 38 \\
$\mathrm{n}$ & 10 & 10 & 10 & 10 & 10 & 10 \\
\hline \multicolumn{1}{c}{ P-PL } & AP & AM & AL & PL & S & H \\
\hline \multicolumn{1}{c}{3} & 22 & 34 & 25 & 27 & 54 & 32 \\
9 & 29 & 41 & 29 & 33 & 63 & 41 \\
5 & 26 & 38 & 26 & 30 & 59 & 37 \\
10 & 20 & 10 & 19 & 20 & 5 & 18 \\
\hline
\end{tabular}

\begin{tabular}{|c|c|c|c|c|c|}
\hline $\mathrm{D}$ & $\mathrm{V}$ & pa & $\mathrm{pm}$ & $\mathrm{pp}$ & Ip \\
\hline $23-33$ & $20-34$ & 209 & 189 & 207 & 605 \\
\hline $28-38$ & $20-34$ & 281 & 241 & 265 & 785 \\
\hline $26-36$ & $20-34$ & 257 & 226 & 247 & 730 \\
\hline 10 & 1 & 10 & 10 & 10 & 10 \\
\hline DS & VS & NDV & TaIII & $\mathrm{TaW}$ & \\
\hline 51 & 55 & 106 & 54 & 13 & \\
\hline 61 & 76 & 132 & 70 & 14 & \\
\hline 56 & 62 & 118 & 65 & 14 & \\
\hline 10 & 10 & 10 & 10 & 10 & \\
\hline
\end{tabular}


H o s t s: Mormoops megalophylla (Peters, 1864) (Chiroptera, Mormoopidae), Myotis nigricans (Schinz, 1821) (Chiroptera, Vespertilionidae), Pteronotus personatus (Wagner, 1843) (Chiroptera, Mormoopidae). New host species: Mormoops blainvillii Leach, 1821, P. macleayii (Gray, 1839), P. quadridens (Gundlach, 1840) (Chiroptera, Mormoopidae).

D i s t r i b u t i o n : Panama, Trinidad. Recorded in Cuba for the first time.

M a t e r i a 1 e x a m i n e d : 40 larvae, Pinar del Rio Province, Vinales, Cueva del Indio, 20-21 Aug. 1965, from P. quadridens; 8 larvae, Habana Province, Guanajay, Cueva de William Palmer, 12 Aug. 1965, from P. quadridens; 2 larvae, Habana Province, Catalina de Guines, Cueva de Mudo, 4 Feb. 1966, from P. quadridens; 2 larvae, Habana Province, Tapaste, Cueva del Indio, 24 May 1965, from $P$. quadridens; 3 larvae, Sancti Spiritus Province, Yaguajay, Cueva Nova Caguane, 11 June 1965, from $P$. macleayii and $P$. quadridens; 4 larvae, Isla de Pinos, Pedernales, Cueva de Murcielagos, 11 Oct. 1965, from $P$. macleayii; 7 larvae, Matanzas Province, Camarioca, Cueva de Santa Catalina, 3 Aug. 1965, from M. blainvillii.

Remarks: A comparison of our measurements with those given by Brennan and Jones (1960) and Vercammen-Grandjean (1968) revealed that our specimens have a smaller scutum $(\mathrm{PW}=59-68$ against $69-72, \mathrm{SD}$ $=34-44$ against 51-54) and shorter setae $(\mathrm{AM}=34-41$ against $45-48, \mathrm{AL}=25-29$ against $32-33, \mathrm{PL}=27-33$ against $33-35, \mathrm{H}=32-41$ against $45-46)$. Probably it is a case of geographic variability.

\section{Tectumpilosum negreai Feider, 1983 Figs. 23-27}

Feider 1983: 120 (adult); de la Cruz and Socarrás 1993: 7, figs. 3-5 (larva).

Diagnosis: $\mathrm{SIF}=7 \mathrm{~B}-\mathrm{N}-3-3111.0000 ; \mathrm{fPp}=\mathrm{B} / \mathrm{B} /$ $\mathrm{BBB} ; \mathrm{fCx}=1.1 .1 ; \mathrm{fSt}=2.2 ; \mathrm{fSc}: \mathrm{PL}>>\mathrm{AM}>\mathrm{AL} ; \mathrm{Ip}=$ $1165 ; \mathrm{fD}=[(8-10)-6]-8-6-4-2-\ldots ; \mathrm{DS}=39 ; \mathrm{VS}=43$; $\mathrm{NDV}=82$.

Description: LARVA. Idiosoma. All surface punctate. Eyes absent. Humeral setae not separated from dorsal setae; 37-42 dorsal idiosomal setae, heavily barbed, arranged [10-6]-8-6-4-2-2 with some variations; 2 pairs of sternal setae; 40-48 ventral setae; total idiosomal setae 79-85. Gnathosoma. Cheliceral blade with tricuspid cap; gnathobase bearing a pair of branched setae; galeala nude; palpal claw 3-pronged; setae on palpal femur and genu branched, palpal tibial setae each with 1-2 branches, in some specimens dorsal seta nude; palpal tarsus with tarsala and 7 branched setae: dorsal seta heavily branched, ventral proximal seta moderately branched, other 5 setae each with 1-2 branches or nude. Scutum. Moderately punctate, trapezoidal, with anterolateral shoulders and with concave anterior and slightly concave posterior margins; $\mathrm{AM}$ base at level of $\mathrm{AL}$ bases; SB very large, slightly posteriad to level of PL bases; PL about twice as long as AL, heavily barbed, situated on posterolateral projections of scutum; $\mathrm{AM}>\mathrm{AL}, \mathrm{AM}$ and $\mathrm{AL}$ with very long thin barbs; flagelliform sensilla with few long branches in distal part. Legs. All 7-segmented, terminating in a pair of claws and a claw-like empodium. Onychotriches absent. Specialised setae long, with pointed apices. Leg I: coxa $1 \mathrm{~B}$; trochanter 1B; basifemur 1B; telofemur 5B; genu 4B, 3 genualae, microgenuala; tibia 8B, 2 tibialae, microtibiala; tarsus 22B, tarsala (32 long), microtarsala, subterminala, parasubterminala, pretarsala. Leg II: coxa 1B; trochanter 1B; basifemur 2B; telofemur 4B; genu $3 \mathrm{~B}$, genuala; tibia $6 \mathrm{~B}, 2$ tibialae; tarsus $16 \mathrm{~B}$, tarsala $(21$ long), microtarsala; pretarsala. Leg III: coxa 1B; trochanter 1B; basifemur 2B; telofemur 3B; genu 3B, genuala; tibia 6B, tibiala; tarsus $15 \mathrm{~B}$.

\section{Standard measurements:}

\begin{tabular}{|c|c|c|c|c|c|c|c|}
\hline & AW & PW & SB & ASB & PSB & SD & P-PL \\
\hline Min & 75 & 95 & 31 & 33 & 16 & 50 & 18 \\
\hline Max & 81 & 98 & 36 & 34 & 18 & 52 & 21 \\
\hline $\mathrm{m}$ & 78 & 96 & 34 & 34 & 17 & 51 & 19 \\
\hline $\mathrm{n}$ & 3 & 3 & 3 & 3 & 3 & 3 & 3 \\
\hline AP & AM & $\mathrm{AL}$ & PL & D & V & pa & $\mathrm{pm}$ \\
\hline 23 & 43 & 38 & 82 & $41-85$ & $40-74$ & 391 & 344 \\
\hline 26 & 49 & 41 & 94 & $52-85$ & $45-79$ & 425 & 371 \\
\hline 24 & 46 & 39 & 88 & $47-85$ & $42-77$ & 406 & 356 \\
\hline 6 & 4 & 5 & 8 & 4 & 4 & 4 & 4 \\
\hline $\mathrm{pp}$ & Ip & DS & VS & NDV & TaIII & TaW & \\
\hline 394 & 1129 & 37 & 40 & 79 & 113 & 20 & \\
\hline 410 & 1199 & 42 & 48 & 85 & 121 & 21 & \\
\hline 403 & 1165 & 39 & 43 & 82 & 117 & 20 & \\
\hline 4 & 4 & 4 & 4 & 4 & 4 & 4 & \\
\hline
\end{tabular}

$\mathrm{H}$ o s $\mathrm{t}$ : Previously only larvae reared in laboratory were studied. Here the first finding of $T$. negreai larvae in nature is reported. Phyllonycteris poeyi Gundlach, 1860 (Chiroptera, Phyllostomidae) is the first known host of this chigger mite.

Distribution: Cuba.

M a t e ri a 1 e x a m i n e d : 5 larvae from the type locality, Sancti Spiritus Province, Yaguajay, Cueva de Colón, 23 Apr. 1965, from P. poeyi.

Remarks: The first description of $T$. negreai larvae (de la Cruz and Socarrás 1993) has obvious errors. Namely, the bases of dorsal seta on palpal tarsus and of dorsal seta on palpal tibia in fig. $4 \mathrm{D}$ are mixed up. Consequently, the authors indicated $\mathrm{fP} p=\mathrm{B} / \mathrm{B} / \mathrm{BBN}$ for this species. They considered one of palpal tarsal setae as specialised subterminala. On leg I only 2 genualae arranged one after the other are figured (de la Cruz and Socarrás 1993; fig. 4 A), third genuala is omitted. Posterolateral setae, situated on scutal projections, are figured and described as extrascutal (ibid., fig. 3). Palpal claw is figured as having only 2 prongs with unusual shapes (ibid., fig. 4 D). Also very unusual numbers of non-specialised leg setae obviously were caused by incorrect counting and, partly, by considering some of such setae as specialised femoralae. On the other hand, arrangement of idiosomal setae, measurements and general appearance of the mite described in the mentioned paper are in good agreement with our data. Therefore there is no doubt that it is the same species. 


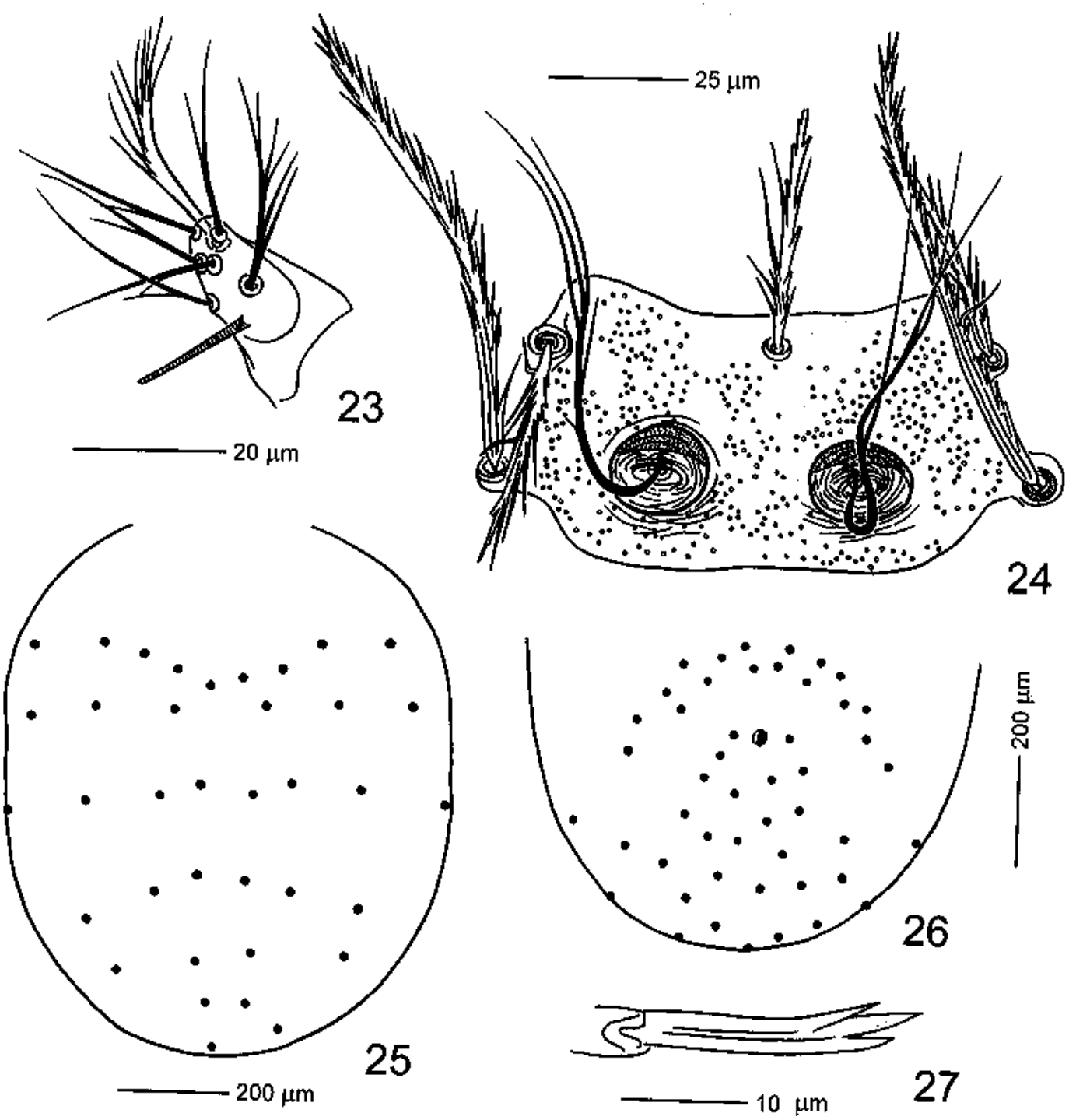

Figs. 23-27. Tectumpilosum negreai Feider, 1983, larva. Fig. 23. Palpal tarsus. Fig. 24. Scutum. Fig. 25. Arrangement of dorsal idiosomal setae. Fig. 26. Arrangement of ventral idiosomal setae. Fig. 27. Palpal claw.

\section{Parasecia manueli (Brennan et Jones, 1960)}

Brennan and Jones 1960: 520, fig. 15 (Trombicula); Vercammen-Grandjean 1965: 38 [Fonsecia (Euneocula)]; Loomis 1966: 191 [Fonsecia (Parasecia)]; Brennan 1969: 666 [Fonsecia (Parasecia)]; Brennan and Lukoschus 1971: 44.

Diagnosis: $\mathrm{SIF}=7 \mathrm{BS}-\mathrm{N}-3-3111.0000 ; \mathrm{fPp}=\mathrm{B} / \mathrm{B} /$ $\mathrm{NNB}$; $\mathrm{fCx}=1.1 .1 ; \mathrm{fSt}=2.2$; fSc: $\mathrm{PL}>\mathrm{AM}>\mathrm{AL} ; \mathrm{Ip}=$ $905 ; \mathrm{fD}=2 \mathrm{H}-6-6-4-2-2 ; \mathrm{DS}=22 ; \mathrm{VS}=19 ; \mathrm{NDV}=41$.

\section{Standard measurements:}

\begin{tabular}{lccccccc}
\hline & AW & PW & SB & ASB & PSB & SD & P-PL \\
\hline Min & 76 & 89 & 31 & 28 & 16 & 47 & 9 \\
Max & 81 & 92 & 35 & 32 & 19 & 49 & 12 \\
$\mathrm{~m}$ & 79 & 90 & 33 & 30 & 18 & 48 & 10 \\
$\mathrm{n}$ & 5 & 5 & 5 & 5 & 5 & 5 & 5 \\
\hline
\end{tabular}

\begin{tabular}{cccccccc}
\hline AP & AM & AL & PL & H & D & V & pa \\
\hline 25 & 49 & 32 & 63 & 56 & $43-61$ & $34-54$ & 315 \\
33 & 55 & 38 & 72 & 65 & $54-68$ & $40-56$ & 333 \\
29 & 51 & 36 & 68 & 60 & $47-65$ & $37-55$ & 325 \\
10 & 3 & 6 & 10 & 7 & 5 & 3 & 5 \\
\hline & & & & & & & \\
\hline pm & pp & Ip & DS & VS & NDV & TaIII & TaW \\
\hline 268 & 297 & 880 & 22 & 17 & 39 & 81 & 17 \\
284 & 319 & 931 & 22 & 20 & 42 & 90 & 19 \\
275 & 305 & 905 & 22 & 19 & 41 & 85 & 18 \\
5 & 5 & 5 & 5 & 5 & 5 & 5 & 4 \\
\hline
\end{tabular}

H o s t s : Many species of reptiles, birds, rodents and marsupials. Only one finding on chiropterans (Molossus sp., Molossidae) has been previously recorded (Brennan and van Bronswijk 1975). New hosts: Pteronotus macleayii (Gray, 1839) (Chiroptera, Mormoopidae) and Erophylla sezecorni (Gundlach, 1860) (Chiroptera, Phyllostomidae). 
D i s t r i b u t i o n : Panama, Colombia, Peru, Trinidad, Surinam. Recorded in Cuba for the first time.

M a t e r i a 1 e x a m i n e d : 3 larvae, Isla de Pinos, Cerro de Guanabana, Cueva de los Lagos, 14 Jan. 1966, from $P$. macleayii; 5 larvae, Isla de Pinos, 26 June 1965, from $E$. sezecorni.

Remarks: In comparison with the original description, our measured specimens are characterised by larger scutum $(\mathrm{AW}=76-81$ against $66, \mathrm{PW}=89-92$ against $76, \mathrm{SD}=47-49$ against 40 ). Probably it is a case of geographic variability.

\section{Beamerella acutascuta Brennan, 1958}

H o s t s : Many bat species. New host: Phyllonycteris poeyi Gundlach, 1860 (Chiroptera, Phyllostomidae).

D i s t r i b u t i o n: Texas, Mexico, Nicaragua, Costa Rica, Panama, Venezuela, Trinidad, Surinam, French Guiana, Bolivia. Recorded in Cuba for the first time.
M a t e ri a 1 e x a m i n e d : 13 larvae, Matanzas Province, Camarioca, Cueva de Santa Catalina, 3 Aug. 1965, from $P$. poeyi; 1 larva, Habana Province, Guanajay, Cueva de William Palmer, 12 Aug. 1965, from P. poeyi.

Blankaartia sinnamaryi (Floch et Fauran, 1956)

D i s t r i b u t i o n : Texas, Florida, Panama, Surinam, French Guiana, Peru, Jamaica, Trinidad. Recorded in Cuba for the first time.

M a t e r i a 1 e x a m i n e d : 1 larva, Isla de Pinos, Cayo Piedra, 9 Oct. 1965, from Glaucidium siju (Orbigny, 1839) (Aves, Strigiformes, Strigidae).

Acknowledgements. We are grateful to Dr. Alfred F. Newton (Field Museum of Natural History, Chicago, Illinois, USA) for the help in the preparation of the English text of our manuscript. We also thank an anonymous reviewer for useful comments.

\section{REFERENCES}

BRENNAN J.M. 1969: Three new species of subgenus Parasecia Loomis (genus Fonsecia) from northeastern Brazil and a key to the included species (Acarina: Trombiculidae). J. Parasitol. 55: 662-666.

BRENNAN J.M., van BRONSWIJK J.E.M.H. 1975: Parasitic mites of Surinam. XXI. New record of Surinam and certain French Guiana chiggers with the description of a new species of Loomisia Brennan \& Reed, 1972 (Acarina: Trombiculidae). J. Med. Entomol. 12: 243-249.

BRENNAN J.M., JONES E.K. 1960: Chiggers of Trinidad, B.W.I. (Acarina: Trombiculidae). Acarologia 2: 493-540.

BRENNAN J.M., LUKOSCHUS F. 1971: Parasitic mites of Surinam. VIII. A new genus and species of chigger, Fauranius atecmartus, and additional records of species (Acarina: Trombiculidae). Bull. South. Calif. Acad. Sci. 70: 42-45.

de la CRUZ J., DANIEL M. 1994: Chigger mites (Acarina: Leeuwenhoekiidae) from Cuba. Folia Parasitol. 41: 71-74.

de la CRUZ J., SOCARRÁS A.A. 1993: Los géneros Ischnothrombium y Tectumpilosum (Acarina: Trombiculidae) en Cuba. Poeyana 437, 14 pp.
FEIDER Z. 1983: Seconde contribution a la connaissance des Trombiculoidea cavernicoles de Cuba. Resultats des Exped. Biospéol. Cubano-Roumaines á Cuba 4: 115-138.

GOFF M.L., LOOMIS R.B., WELBOURN W.C., WRENN W.J. 1982: A glossary of chigger terminology (Acari: Trombiculidae). J. Med. Entomol. 19: 221-238.

LOOMIS R.B. 1966: A new genus, Fonsecula, and a new subgenus (Parasecia) of the genus Fonsecia (Acarina, Trombiculidae). Bull. South. Calif. Acad. Sci. 65: 190191.

LOOMIS R.B. 1969: Chiggers (Acarina, Trombiculidae) from vertebrates of the Yucatan Peninsula, Mexico. Univ. Kans. Mus. Nat. Hist., Misc. Publ., 50. 22 pp.

VERCAMMEN-GRANDJEAN P.H. 1965: Trombiculinae of the World. Synopsis with Generic, Subgeneric, and Group Diagnoses (Acarina, Trombiculidae). George Williams Hooper Foundation for Medical Research, University of California Medical Center, San Francisco, 192 pp.

VERCAMMEN-GRANDJEAN P.H. 1968: Revision of the genus Myotrombicula Womersley and Heaslip, 1943 (Trombiculidae: Acarina). Acarologia 10: 65-85. 